\title{
An experimental investigation of the single-sided infiltration through doorways of the cold store
}

Shen Tian ${ }^{\mathrm{a}, \mathrm{b}, \mathrm{c}}$, Yuping Gao ${ }^{\mathrm{a}, \mathrm{b}, \mathrm{c}}$, Shuangquan Shao ${ }^{\mathrm{a}, \mathrm{b}, *}$, Hongbo $\mathrm{Xu}^{\mathrm{a}, \mathrm{b}}$, Changqing $\operatorname{Tian}^{\text {a.b }}$

a Key Laboratory of Cryogenics, Technical Institute of Physics and Chemistry, Chinese Academy of Sciences, 29 Zhongguancun East Road, Beijing 100190, PR China

${ }^{\mathrm{b}}$ Beijing Key Laboratory of Thermal Science and Technology, Technical Institute of Physics and Chemistry, Chinese Academy of Sciences, 29 Zhongguancun East Road, Beijing 100190, PR China

${ }^{\mathrm{c}}$ University of Chinese Academy of Sciences, No.19A Yuquan Road, Beijing 100049, PR China

* Corresponding author. Tel.: +86 1082543433.

E-mail address: shaoshq@mail.ipc.ac.cn (S. Q. Shao)

Abstract: The frequent infiltration through doorways accounts for a very large proportion of the total heat load of cold stores. Understanding the influence factors, along with wider range of experiments, clearly support the accurately predict and cut down the infiltration. This paper provides a series of experimental investigations on the infiltration under different conditions. The experiments take factors of various door opening sizes, temperature differences and on/off of the cooling fans into account. It is observed that the infiltration flow rate stays steady while the indoor temperatures of the local probes change vigorously. The infiltration air volume 
changes linearly with the door open time, whether the cooling fans are turned on or off. Moreover, the air mixture effect related to the cooling fans can counteract the infiltration process.

Key words: infiltration; doorways; single-sided; cold store

\begin{tabular}{|c|c|}
\hline \multicolumn{2}{|c|}{ Nomenclature } \\
\hline$A$ & area $\left(\mathrm{m}^{2}\right)$ \\
\hline$C$ & concentration (ppm) \\
\hline$H$ & height (m) \\
\hline$Q$ & flow rate $\left(\mathrm{m}^{3} \mathrm{~s}^{-1}\right)$ \\
\hline$T$ & temperature $\left({ }^{\circ} \mathrm{C}\right)$ \\
\hline$u$ & standard uncertainty \\
\hline$V$ & volume $\left(\mathrm{m}^{3}\right)$ \\
\hline \multicolumn{2}{|c|}{ Greek symbols } \\
\hline$\Delta T$ & temperature difference $\left({ }^{\circ} \mathrm{C}\right)$ \\
\hline$\sigma$ & standard deviation \\
\hline$\rho$ & density $\left(\mathrm{kg} \mathrm{m}^{-3}\right)$ \\
\hline \multicolumn{2}{|c|}{ Subscripts } \\
\hline$c$ & cold store \\
\hline$d$ & door \\
\hline$e$ & environment \\
\hline$f$ & final \\
\hline$i$ & initial \\
\hline
\end{tabular}




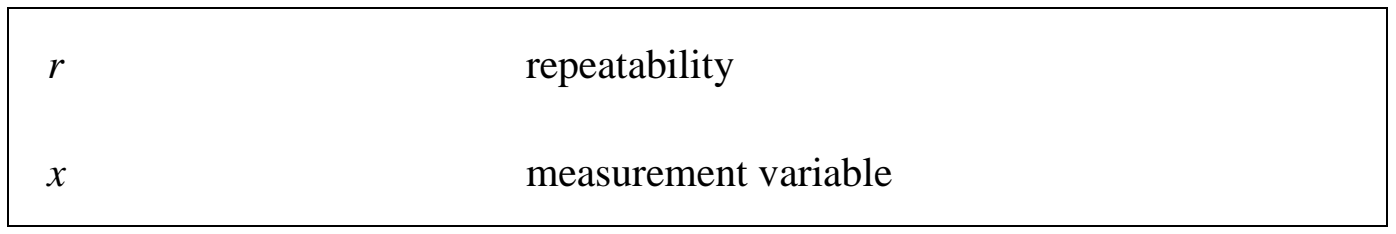

\section{Introduction}

Cold stores are key infrastructures to compose the cold chain system. It is reported that there are 60-70 million $\mathrm{m}^{3}$ cold stores in Europe (Evans et al., 2014a) while in China this number is about 160 million in 2015. Cold store exhibits a much lower indoor temperature than other buildings. There is a considerable amount of energy consumed by it. The mean Specific Energy Consumption (SEC) is 56.1, 73.5 and 61.2 $\mathrm{kWh} \mathrm{m}^{-3}$ year $^{-1}$ for chilled, frozen and mixed stores respectively according to a recent survey (Evans et al., 2014a). With the development of cold chain and the increased expectation for fresh and safety food from consumers, the total amount of cold stores may continuously increase as well as the total energy consumption.

Electricity consumption of refrigeration systems accounts for about $60-70 \%$ of the total electrical energy use of cold store (Evans et al., 2014b), and this part of electricity is mainly used to remove the heat load. It implies that on the demand of energy consumption reduction for cold stores, a detailed analyzation of the heat load factors is needed. Among different kinds of heat load, the most obvious contribution to the load is the heat obtained through the insulated envelopes and the infiltration load through doors. Indeed, the intermittent infiltration heat load due to frequently door open may be responsible for more than half of the total heat load of the cold store (Chen et al., 2002). For this reason, attentions were paid on the measurement and calculation of the infiltration through doors. Foster et al. $(2002,2003)$ conducted 
a direct experiment of infiltration with an unprotected door. A cold store with internal dimensions of $5 \times 6 \times 4 \mathrm{~m}$ high and with a large single opening 2.3 wide $\times 3.2 \mathrm{~m}$ high was tested. The tracer gas method was used to determine the total volume and airflow through the doorways. The mean infiltration flow rates of different door geometry sizes and indoor temperatures were obtained by the door open time linear fitted with the total volume of the infiltration flow. Chen et al. (2002) experimentally tested infiltration rates through opening doors into 7 commercial cold stores. The contributions of air-tightness, door openings, door protections and traffic through the doors were considered and summed. The infiltration rate was measured by means of tracer gas decay technique. An empirical equation to calculate the infiltration flow rate was proposed. Micheaux et al. (2015) experimentally studied heat and mass infiltration rates of a refrigerated truck during the door open. The infiltration flow rate was calculated based on the velocity measurement in the doorway plane. The abovementioned experimental researches provide a series of detailed data on the instantaneous single-sided infiltration through opening doors. However, the authors also mentioned that more work is needed with wider range of cold stores and door sizes to obtain more general conclusions (Chen et al., 2002; Micheaux et al. 2015). The infiltration through doors, analogous to the single-sided natural ventilation, is the ventilation that warm air entering at the top of the opening and cold air flowing out at the bottom of the opening (Jiang et al., 2001). In the study of single-sided natural ventilation through openings, steady flow-field is often considered to be dominant, while the transient flow is not so important. However, the infiltration caused by the 
temporary door open of cold store exhibits some transient characteristics. As observed by Micheaux et al. (2015), the infiltration rate increases rapidly and reaches its maximal value in a small period of time after the door open. Then it quickly declines with time. Gan et al. (2000) points out that the mechanism of this flow pattern is complex and produces larger magnitude of air change rate than steady flow. Therefore, in order to properly predict the infiltration as a function of time and to get an accurate estimation of the heat load, it is necessary to employ more experimental and numerical techniques to analyze this peculiar transient infiltration mechanism in depth.

Most of the previous studies investigated the single-sided natural ventilation based on three methods: empirical models (Dascalaki et al., 1999; Larsen et al., 2008; Caciolo et al., 2013; Wang et al., 2015; Tang et al., 2015), experimental measurements (Dascalaki et al., 1996; Jiang et al., 2003; Li et al., 2014; Grabe et al., 2014), and computational fluid dynamic (CFD) simulations (Gan et al., 2000; Caciolo et al., 2012). Among these studies, more attentions were paid on the experimental measurements for the demand of the validation of the two other methods, especially the measurement of the infiltration rate. For the determination of the air infiltration rate, the tracer gas technologies were usually used as the reference methods (Ghazi et al., 2014). The concentration decay method, which was one of the tracer gas methods, seemed to be easy to implement and accurate enough. And the use of $\mathrm{CO}_{2}$ as a tracer gas was employed in some researches (Li et al., 2014; Grabe et al., 2014; Cui et al., 2015). For the comparisons between experiments and CFD, the local air temperature 
at different locations was also measured in some literatures (Caciolo et al., 2012).

From the above review, it can be concluded that the combination of the measurements of the infiltration rate and local temperature is necessary for the study of the single-sided natural ventilation.

The previous studies are mainly focused on the specific type of cold store with almost same height of door and cold store. In this paper, a series of experiments are carried out in an arranged cold store, in which the height ratio between the door and the cold store is 1:2. For this case, such as cold stores with high floor height and low door height, the air interchange process may experience a more curved flow path (through the top half of the door to get to the roof of the cold store) and will provide a different time-varying infiltration. However, few detailed experimental results are available for this case. What's more, the mixing function of the cooling fans while the door opens can also affect the infiltration. Nevertheless, it is not considered in the previous studies. Therefore, this particular cold store is selected and tested. Measurements of the single-sided infiltration with three door opening rates, two temperature differences and the on/off of the cooling fans are carried out under comparable conditions. The measurement procedure, the comparison between different comparable conditions and the uncertainty analysis of the results are demonstrated and explained in this study.

\section{Experimental setup}

\subsection{Test cold store and measurement devices}

The arranged test cold store is located inside a laboratory as shown in Fig.1, so that the effect of the wind on the infiltration flow could be excluded. The laboratory has a 
dimension length $\times$ width $\times$ height of $10 \mathrm{~m} \times 7.2 \mathrm{~m} \times 5 \mathrm{~m}$, giving a total air volume of $360 \mathrm{~m}^{3}$. The temperature of the laboratory space is relatively stable and maintains at a certain level of $17 \pm 1^{\circ} \mathrm{C}$. However, the humidity parameter is not controlled. The cold store is $4 \mathrm{~m}$ long, $3 \mathrm{~m}$ wide and $4.2 \mathrm{~m}$ high for the outer dimensions and is made from $0.1 \mathrm{~m}$ thickness polyurethane foam insulation, i.e. has a $42.56 \mathrm{~m}^{3}$ inner volume. The doorway plane has a single fast sliding door with a dimension width $\times$ height of $1.175 \mathrm{~m} \times 1.98 \mathrm{~m}$. Different opening sizes are created by the door opening rates. A R22 refrigeration unit is used to cooling down the indoor air. And the unit combines with the on/off control which can realize the regulation of the indoor temperature. Cooling fans which can be separately controlled are placed in front of the evaporator to help to mixing and cooling the air quickly. $\mathrm{A} \mathrm{CO}_{2}$ gas tank controlled by a solenoid valve is used to inject $\mathrm{CO}_{2}$ gas into the cold store. The outlet of the $\mathrm{CO}_{2}$ delivery pipe is placed directly below the evaporator.

The sampling method based on high precision NDIR gas sensors is used to measure the concentration of the $\mathrm{CO}_{2}$ gas. Three sampling probes are mounted, two of them are placed vertically in the center of the cold store (Fig.1), and the other is placed outside of the door (on the top of the door, $2.5 \mathrm{~m}$ high from the floor). These NDIR gas transmitters have a precision of $\pm 0.2 \%$ and the response time of $15 \mathrm{~s}$.

Thermocouple is also attached on each of the gas transmitters to measure the local temperature. It is worth to note that it is very hard to measure a meaningful air temperature in a large air volume which has such rapid transients. Therefore, the local measurements are only used to qualitative analyze the local temperature variations. 


\subsection{Measurement producer}

First, the air tightness of the cold store is experimentally determined. It follows the procedure that: the door is closed, the refrigeration unit and the fans are turned on to cool down the cold store, and $\mathrm{CO}_{2}$ is injected until an initial concentration of 5000 ppm and a temperature difference between indoor and outdoor of around $50{ }^{\circ} \mathrm{C}$ is achieved. Then accumulate data for 30 minutes. This test is replicated three times and the average airtightness of the cold store is $6.4 \times 10^{-4} \mathrm{~m}^{3} \mathrm{~s}^{-1}$. This leakage of air is three or more orders of magnitude less than the infiltration as observed during the door open, which can be neglected.

The initial procedure of the infiltration experiments are the same as the air tightness test. But the initial conditions are different. Two temperature differences around $50{ }^{\circ} \mathrm{C}$ and $30{ }^{\circ} \mathrm{C}$ are established respectively. The initial concentration of the $\mathrm{CO}_{2}$ gas is also around $5000 \mathrm{ppm}$. After reaching the initial conditions, the door opening processes for the infiltration experiments follow the procedure categories that:

(1) Three door opening sizes: full opening, 2/3 opening and 1/2 opening.

(2) On/off of the fans during the door open.

(3) Six door open time (include the opening time of the door, which is about 1-2 s): $5 \mathrm{~s}$, $10 \mathrm{~s}, 20 \mathrm{~s}, 30 \mathrm{~s}, 40 \mathrm{~s}$ and $60 \mathrm{~s}$.

Before the door opens, the measured parameters are guaranteed to be stabled, especially for the cases that the fans are turned from on to off. The compressor of the refrigeration unit is turned off when the indoor temperature reaches the initial setting value. After the door closed, the fans are maintained or turned on to mix the indoor air. 
In summary, 72 groups of experimental data are obtained. What's more, each group is repeated three times for the analysis of the repeatability uncertainty.

\section{Data analysis}

\subsection{Methods for determine infiltration air volume}

As above mentioned, the sampling method is used, which measures the initial $\left(C_{i}\right)$, final $\left(C_{f}\right)$ and environment $\left(C_{e}\right)$ concentration of the $\mathrm{CO}_{2}$ gas. Based on these parameters, the equation for determine the infiltration air volume $\left(V_{\text {total }}\right)$ can be written as (Ghazi et al., 2014; Cui et al., 2015):

$$
V_{\text {total }}=V_{c} \cdot \ln \left(\frac{C_{i}-C_{e}}{C_{f}-C_{e}}\right)
$$

where $V_{c}$ is the inner volume of the cold store.

It should be noted that the sampling point can only measure the local concentration, so Eq. (1) may be not accurate enough for the cases that the flow-field is not uniform. To conquer this problem, the measurement is carried out based on the concentration difference of the period of time of the door open, i.e. calculating the total infiltration volume by the initial and final concentration of the tracer gas. Based on this method, a series of infiltration air volumes corresponding to the specific door open time are obtained. The indoor air is guaranteed to be mixed sufficiently before the door is open and after the door is closed.

\subsection{Uncertainty analysis}

There are three measurement uncertainties need to be analyzed in this study, which are correspond to the initial temperature difference, infiltration air volume and local temperature. Seven of the sources of the measurement uncertainties are introduced 
into the experiments: (1) the indoor temperature $T_{i},(2)$ the environment temperature $T_{e}$, (3) the initial and final $\mathrm{CO}_{2}$ concentrations in the cold store $C_{i}$ and $C_{f}$, (4) $\mathrm{CO}_{2}$ concentration in the environment $C_{e},(5)$ the cold store inner volume $V_{\mathrm{c}},(6)$ measurement repeatability and (7) the rated accuracy of the sensors. Each of the measurement uncertainties is found by the uncertainty of the measurement, repeatability and the rated accuracy of the sensors. The rated accuracy is $\pm 0.1^{\circ} \mathrm{C}$ of the thermocouples, $\pm 0.2 \%$ full scale of the $\mathrm{CO}_{2}$ concentration sensors and $\pm 0.001 \mathrm{~m}$ of the measured length. The combined standard uncertainties can be given by a uniformed formula, which can be written as:

$$
u\left(f_{m}\right)=\left[\sum_{i=1}^{n}\left(\frac{\partial f_{m}}{\partial x_{i}}\right)^{2} \sigma_{i}^{2}+u_{r}^{2}+\sum_{i=1}^{n}\left(\frac{\partial f_{m}}{\partial x_{i}}\right)^{2} u_{s_{i}}^{2}\right], m=1,2,3
$$

where:

$f_{1}, f_{2}$ and $f_{3}$ represent the temperature difference, infiltration air volume and local temperature, respectively.

$x$ is the variable upon which $f_{m}$ depends.

$n$ is the total number of the measurement variables.

$u$ is the standard uncertainty.

$\sigma$ is the standard deviation of the variable.

$r$ represent the repeatability and $s$ stands for the sensor.

A total expanded uncertainty with a certain confidence level $95 \%$, can be obtained by multiplying the combined standard uncertainty $u\left(f_{m}\right)$ by a confidence factor $(k=2)$.

\section{Results and discussions}

\subsection{Infiltration air volume and flow rate}


Table 1 summarizes the results for the calculated infiltration air volumes with $95 \%$ confidence interval. It is worth noting that the door open time consists of time required for the open process (about 1-2s) and time remained the door open. The close process is not considered. The Results show that the largest uncertainty is $3.94 \mathrm{~m}^{3}$ (highlighted in bold in Table 1), the rated measurement error is $\pm 9 \%$, indicating that the measurements have good repeatability and precisions.

Fig. 2 shows the typical trend lines and error bars of the infiltration air volume and flow rate in the experiments. In the left of this figure, each point represents the mean air volume value corresponding to the three replicated measurements. In the right, the flow rates are calculated by dividing the arithmetic mean air volumes of two door open time by the time interval. As observed, the infiltration air volume increases linearly with the door open time. The infiltration flow rate changes rapidly and reaches a high flow rate of $1.05 \mathrm{~m}^{3} \mathrm{~s}^{-1}$ at few seconds (less than 10 seconds) after the door open, and then maintains at a certain level with small disturbance. This is not match with the results concluded by Micheaux (2015), where the flow rate is varied intensely with time (as shown in Fig 2, red line). One possible reason is that the indoor flow-field is not uniform during the door open. For a relatively small door open size in the experiments, the dense cold air does not flow all out before $60 \mathrm{~s}$. The buoyancy-driven effect, which is driven by the density difference, may be still functioning on the air flow. Moreover, the initial density of the indoor and outdoor air has a very little difference. The density is not sensitive to the temperature variation. What's more, with the enhancement of the flow inertia, the infiltration flow rates 
become steady.

Fig. 3 shows the typical variation of the local indoor temperatures during the door open. In this figure, indoor temperature values are measured by two thermocouples: top and bottom, corresponding to the position of the gas sensors in Fig. 1.Comparing the two local temperatures, a sudden rise of the temperature appears earlier and a high value is obtained whole way at the top than the bottom. This implies that the indoor temperature field is heterogeneous.

\subsection{Influence of the door opening size}

The Comparison of infiltration air volumes with different door opening sizes is shown in Fig. 4. Straight lines are fitted through zero to the data. The correlation coefficients give good agreements for the linear fitting, as it globally beyond 0.99 . The slopes of the lines are proportional and have the linear relation with the door width. For example, in the case of $\Delta T=50^{\circ} \mathrm{C}$ and fans off, the slope ratio between the lines of full opening and $2 / 3$ opening is 0.69 , very close to $2 / 3$. What's more, this linear relationship is general, whether the fans are turned on/off.

\subsection{Effect of the cooling fans}

Table 2 shows the linear fitted slopes in Fig. 4, which representing the average flow rate for the same temperature difference and same opening rate conditions in the case of the measurements with or without the fans operating. It is observed that the wind created by the fans has a negative effect on the infiltration flow rate for all the ratios are beyond ratio 1.0. In terms of the infiltration through doorways of cold stores, it is a buoyancy-driven flow caused by the temperature difference. As same as the other 
buoyancy-driven flow patterns such as mentioned in the literature (Gan et al., 2000), there is an effective area in the indoor side, and this area expands with the increase of the door open time. However, the mixing effect of the cooling fans can also help to strength the extension of the area. This can be verified by Fig. 5. In comparison to the case of the fans are turned off, the sudden rise of the temperature appears earlier when the fans are turned on. It means that the warm air spreads faster to the measurement point. It can also be deduced that the warm air is much easier to get to the deep inside of the cold store. With the faster extension of the effective area, a higher indoor temperature is obtained. Thus the temperature difference is smaller overall as well as the infiltration when the fans are turned on.

Table 2 shows that in the door fully open and the temperature difference of $50{ }^{\circ} \mathrm{C}$ condition, the ratio between the flow rates in the case without and with the fans operating is 1.49 . However, when the opening rate changes to $67 \%$, a ratio of 1.53 is obtained. From the temperature difference aspect, the ratio decrease with the increase of the temperature difference. These trends imply that this ratio varies inversely according to the door width and the temperature difference.

\subsection{Influence of temperature differential}

As shown in Fig. 4, the slope of the fitting line of small temperature difference is less than the high one in the same condition. Here, in order to analyze the influence of the temperature differential, a semi-empirical equation (which is recommended by ASHRAE to predict the infiltration flow rate of cold store) by Gosney is introduced. The equation is expressed as: 


$$
Q=0.221 A_{d}\left(g H_{d}\right)^{0.5}\left[\frac{\left(\rho_{i}-\rho_{e}\right)}{\rho_{\text {avg }}}\right]^{0.5}\left[\frac{2}{1+\left(\rho_{e} \rho_{i}^{-1}\right)^{1 / 3}}\right]^{1.5}
$$

As can be seen in the equation, the infiltration flow rate relates to the initial and environment air density, or relates to the initial and environment air temperature. By applying the Buoyancy assumption, this equation can also be expressed as:

$$
Q=0.221 A_{d}\left(g H_{d}\right)^{0.5}\left[\frac{\left(T_{e}-T_{i}\right)}{T_{\text {avg }}}\right]^{0.5}\left[\frac{2}{1+\left(T_{i} T_{e}^{-1}\right)^{1 / 3}}\right]^{1.5}
$$

This formula can be applied on analyzing the influence of the temperature difference by maintaining the geometry size of the door fixed. Table 3 shows the comparison results of the ratio between the slopes in Fig. 4 and the ratio between the predicted $Q$ s from Eq. (4). The predicted $Q$ s are calculated with the initial temperature of indoor and outdoor. A similar result with largest error of $7.33 \%$ is observed which means that the influence of the temperature differential follows the principle stated by Eq. (4). Therefore, the infiltration of other temperature differences can also be approximately deduced by Eq. (4).

\section{Conclusions}

This work is carried out to study the infiltration through open doors of cold store. Experiments are performed for different door opening sizes, initial temperature differences and on/off of the cooling fans. The infiltration air volume and flow rate are calculated based on the sampling method of tracer gas technology. After that, several factors (door opening size, fans' on/off and temperature difference) which can influence the infiltration are analyzed. The following conclusions can be drawn:

(1) For the case that the dimension of the door is small in comparison to the 
dimension of the cold store, the infiltration is more stable than the opposite case. In other words, the infiltration flow rate does not change intensely with door open time. (2)The comparison of infiltration air volumes with different door opening sizes shows that the infiltration air volume has a linear relation with the door's width.

(3) When the cooling fans are turned on, the effective area related to the infiltration in the cold store is strengthened. This strengthened turbulent area increases the indoor temperature more rapidly. As a consequence the effective temperature difference between indoor and outdoor decreases more rapidly. Therefore, the infiltration flow rate is lower than that cooling fans are turned off.

(4) In the cases with the cooling fans on, local turbulence produced by the cooling fans can weaken the formation of streamline flow. It can be deduced that the horizontal direction flow, which is parallel to the doorway plane, can counteract the infiltration process. Therefore, a practical way to avoid the infiltration may be installing an air curtain on the side face of the door frame, instead of on the top of the door frame. Thus a horizontal direction wind can help to weaken the infiltration in a better way.

(5) Moreover, the influence of the temperature difference follows the principle stated by an empirical equation proposed by Gosney.

Regarding the infiltration through doorways of cold stores, case of different height ratio between the door and the cold store shows different time-varying infiltration characters. Further studies may be the infiltration study of huge-scale (about 40-60 m high) cold stores, transient prediction models which can be applied to all the cases, the 
indoor filed test, verification of the affected area of infiltration and the install position of the air curtain to avoid the heat loss while the door is open.

\section{Acknowledgement}

This work is funded by the Key International Program of Chinese Academy of Sciences (CAS-DOE, 1A1111KYSB20150014).

\section{References}

Caciolo M., Stabat P., Marchio D., 2012. Numerical simulation of single-sided ventilation using RANS and LES and comparison with full-scale experiments. Building and Environment 50, 202-213.

Caciolo M., Cui S. Q., Stabat P., Marchio D., 2013. Development of a new correlation for single-sided natural ventilation adapted to leeward conditions. Energy and Buildings 60, $372-382$.

Chen P., Cleland D. J., Lovatt S. J., Bassett M. R., 2002. An empirical model for predicting air infiltration into refrigerated stores through doors. International Journal of Refrigeration 25, 799-812.

Cui S. Q., Cohen M., Stabat P., Marchio D., 2015. $\mathrm{CO}_{2}$ tracer gas concentration decay method for measuring air change rate. Building and Environment 84, 162-169.

Dascalaki E., Santamouris M., Argiriou A., Helmis C., Asimakopoulos D. N., Papadopoulos K., Soilemes A., 1996. On the combination of air velocity and flow measurements in single sided natural ventilation configurations. Energy and Buildings 24, 155-165.

Dascalaki E., Santamouris M., Asimakopoulos D. N., 1999. On the use of deterministic and intelligent techniques to predict the air velocity distribution on external openings in 
single-sided natural ventilation configurations. Solar Energy 66, 223-243.

Evans J.A., Hammond E.C., Gigiel A. J., Foster A. M., Reinholdt L., Fikiin K., Zilio C., 2014. Assessment of methods to reduce the energy consumption of food cold stores. Applied Thermal Engineering 62, 697-705.

Evans J.A., Foster A.M., Huet J. M., Reinholdt L., Fikiin K., Zilio C., Houska M., Landfeld A., Bond C., Scheurs M., Sambeeck T.W.M. van, 2014. Specific energy consumption values for various refrigerated food cold stores. Energy and Buildings 74, 141-151.

Foster A. M., Barrett R., James S. J., Swain M. J., 2002. Measurement and prediction of air movement through doorways in refrigerated rooms. International Journal of Refrigeration 25, $1102-1109$.

Foster A. M., Swain M. J., Barrett R., James S. J., 2003. Experimental verification of analytical and CFD predictions of infiltration through cold store entrances. International Journal of Refrigeration 26, 918-925.

Gan G., 2000. Effective depth of fresh air distribution in rooms with single-sided natural ventilation. Energy and Buildings 31, 65-73.

Ghazi C. J., Marshall J. S., 2014. A CO 2 tracer-gas method for local air leakage detection and characterization. Flow Measurement and Instrumentation 38, 72-81.

Grabe J. V., Svoboda P., Bäumler A., 2014. Window ventilation efficiency in the case of buoyancy ventilation. Energy and Buildings 72, 203-211.

Jiang Y., Chen Q. Y., 2001. Study of natural ventilation in buildings by large eddy simulation. Journal of Wind Engineering and Industrial Aerodynamics 89, 1155-1178.

Jiang Y., Chen Q. Y., 2003. Buoyancy-driven single-sided natural ventilation in buildings with 
large openings. International Journal of Heat and Mass Transfer 46, 973-988.

Li H., Li X. F., Qi M. W., 2014. Field testing of natural ventilation in college student dormitories (Beijing, China). Building and Environment 78, 36-43.

Larsen T. S., Heiselberg P., 2008. Single-sided natural ventilation driven by wind pressure and temperature difference. Energy and Buildings 40, 1031-1040.

Micheaux T. L., Ducoulombier M., Moureh J., Sartre V., Bonjour J., 2015. Experimental and numerical investigation of the infiltration heat load during the opening of a refrigerated truck body. International Journal of Refrigeration 54, 170-189.

Tang Y. Q., Li X. F., Zhu W., Cheng P. L., 2015. Predicting Single-sided Airflow Rates Based on Primary School Experimental Study. Building and Environment 98, 71-79.

Wang H. J., Chen Q. Y., 2015. Modeling of the impact of different window types on single-sided natural ventilation. Energy Procedia 78, 1549 - 1555. 


\section{Figure Captions}

Fig. 1. The configuration of the test cold store.

Fig. 2. Trend lines of the infiltration air volume and flow rate, comparison between Micheaux's data and experimental results with condition of door full opening, $50{ }^{\circ} \mathrm{C}$ temperature difference and fans off.

Fig. 3. Variation of the indoor temperatures, with condition of door full opening, 50 ${ }^{\circ} \mathrm{C}$ temperature difference and fans off.

Fig. 4. Comparison of infiltration air volumes with different door opening sizes: (a) fans off, (b) fans on.

Fig. 5. Indoor temperatures measured during the door open, with different conditions of temperature differences and on/off of the mixing fans: (a) full opening, (b) 2/3 opening, (c) 1/2 opening. 


\section{Table Captions}

Table 1. Overview of the experimental conditions and calculated infiltration air volumes by using the sampling method.

Table 2. Average flow rate (slope of the fitted line in Fig. 4) and the ratio between the flow rates in the case with and without the fans operating.

Table 3. Comparison results of the ratio between the slopes in Fig. 4 and the ratio between the predicted $Q$ s from Eq. 4 (with same opening rate and state of the cooling fans). 

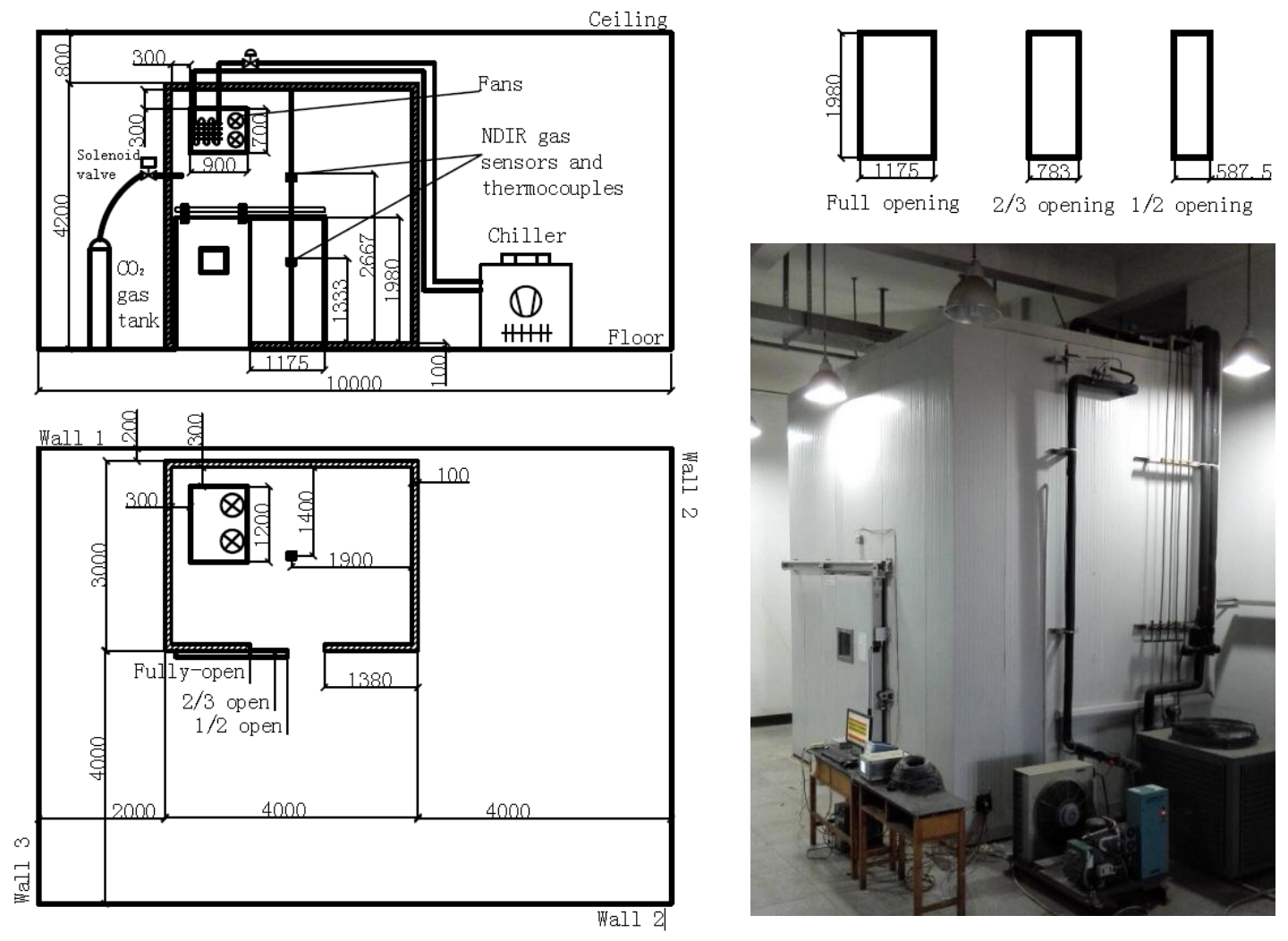

Fig. 1 The configuration of the test cold store 

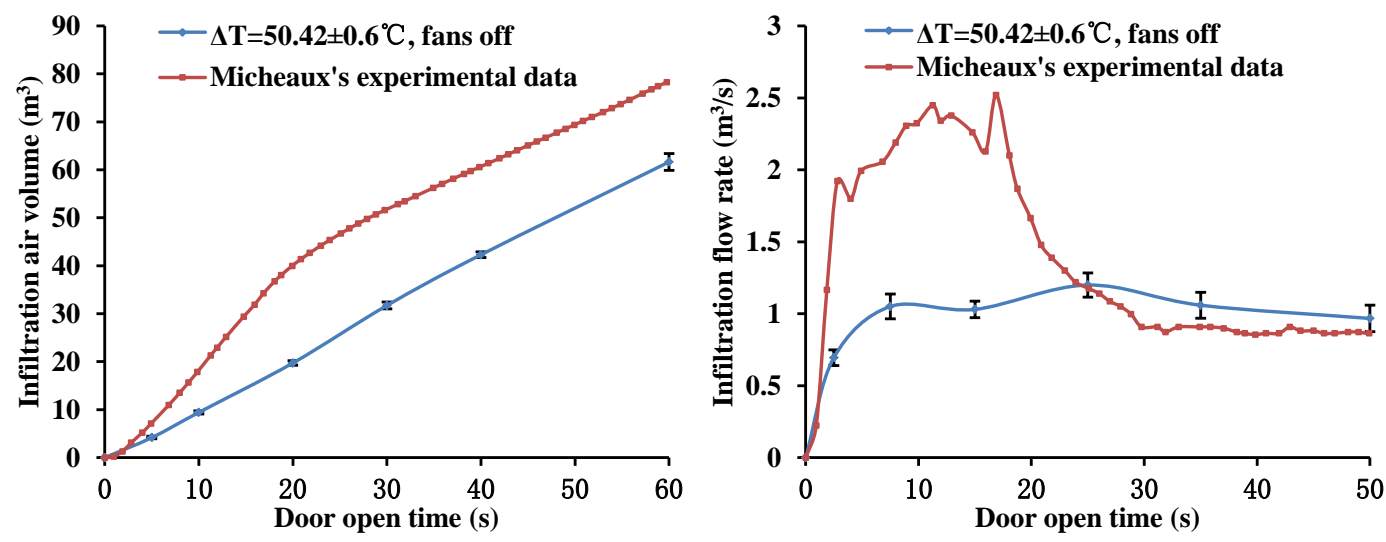

Fig. 2 Trend lines of the infiltration air volume and flow rate, comparison between

Micheaux's data and experimental results with condition of door full opening, $50{ }^{\circ} \mathrm{C}$ temperature difference and fans off 


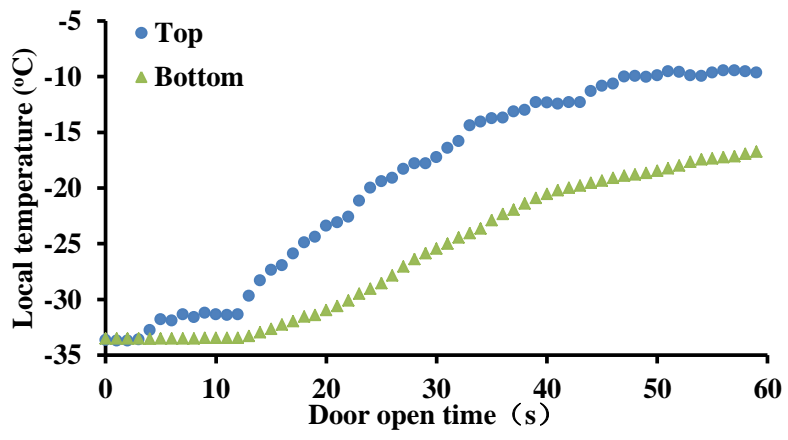

Fig. 3 Variation of the indoor temperatures, with condition of door full opening, $50{ }^{\circ} \mathrm{C}$ temperature difference and fans off 

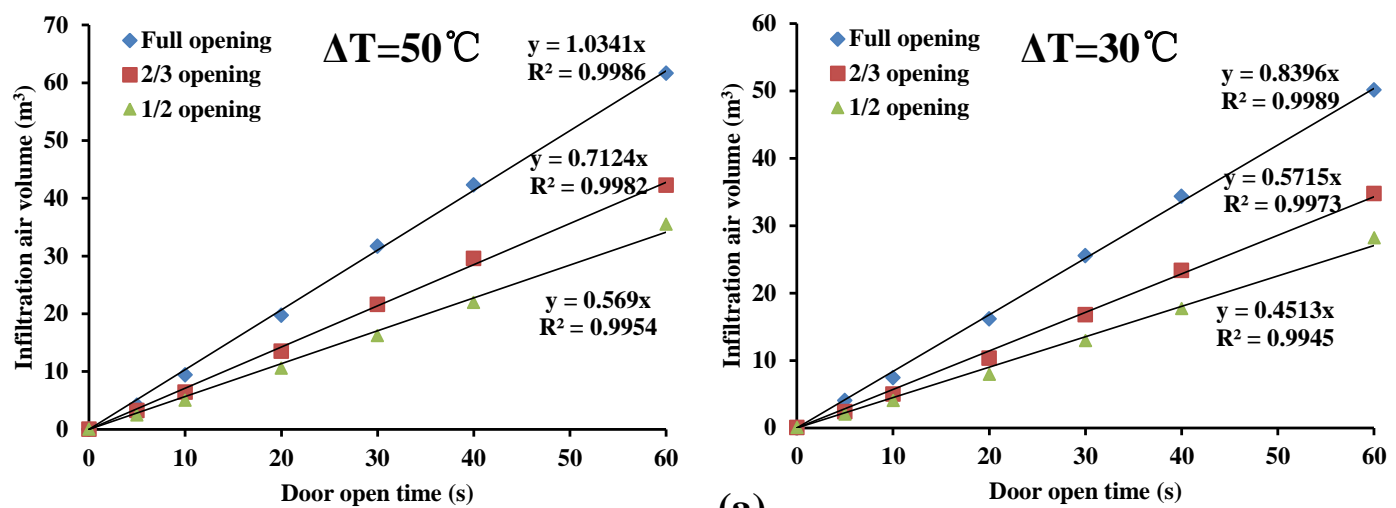

(a)
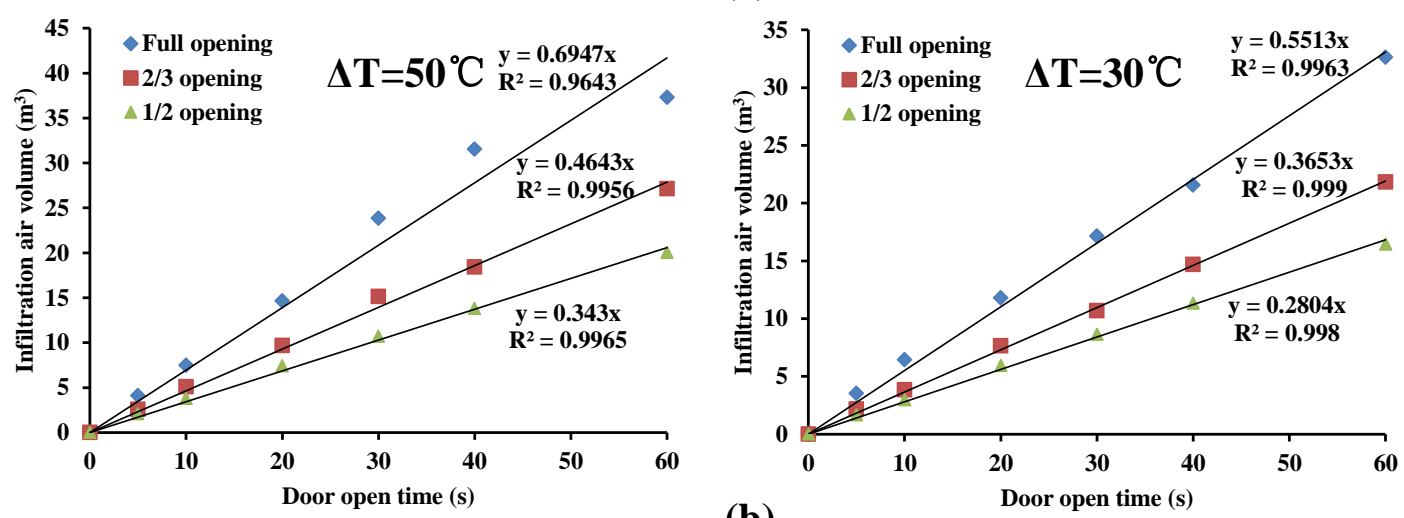

(b)

Fig. 4 Comparison of infiltration air volumes with different door opening sizes: (a)

fans off, (b) fans on 

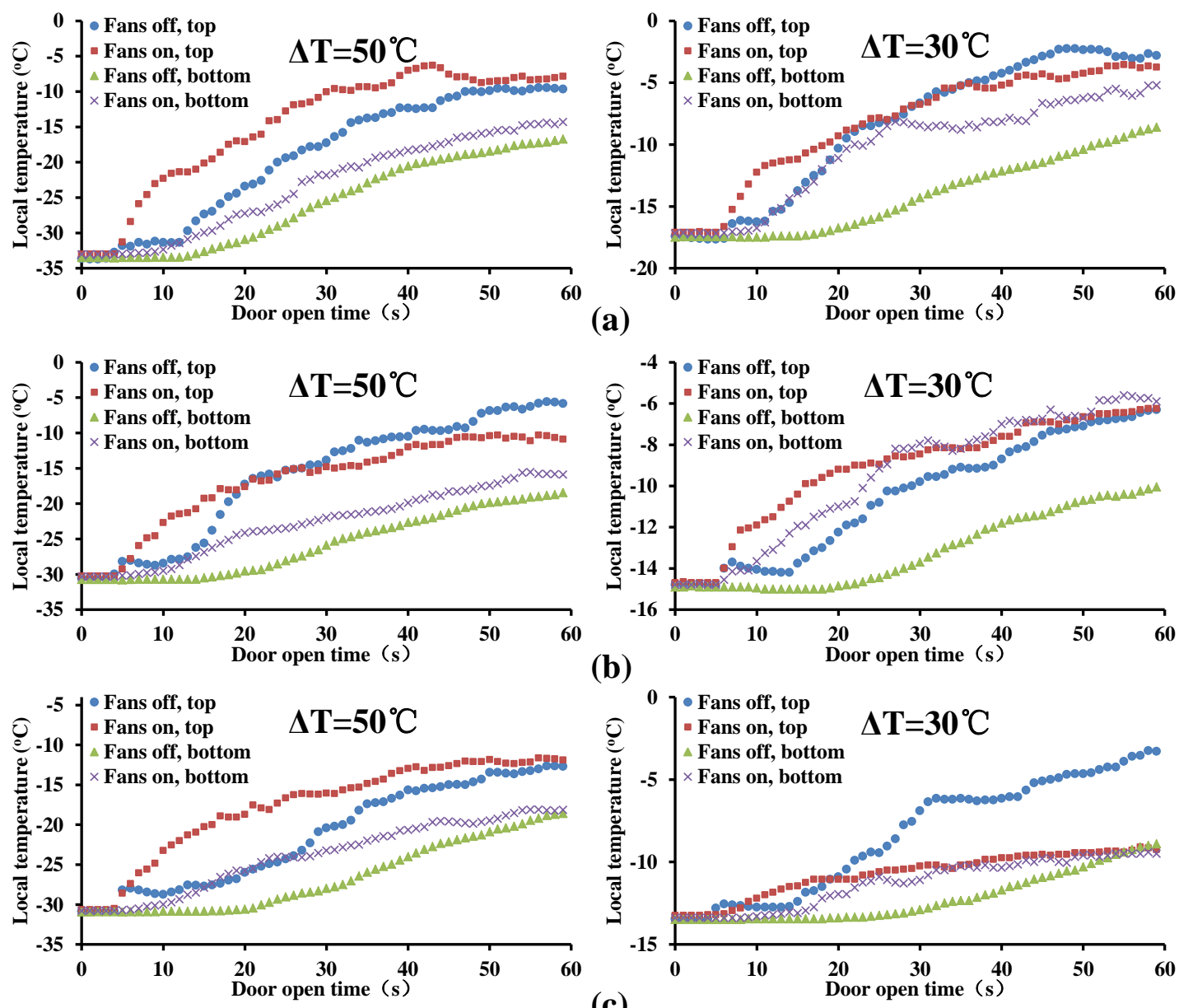

(c)

Fig. 5 Indoor temperatures measured during the door open, with different conditions

of temperature differences and on/off of the mixing fans: (a) full opening, (b) 2/3

opening, (c) 1/2 opening 
Table 1 Overview of the experimental conditions and calculated infiltration air volumes by using the sampling method

\begin{tabular}{|c|c|c|c|c|c|c|c|c|}
\hline \multirow{3}{*}{$\begin{array}{c}\text { Door } \\
\text { opening rates }\end{array}$} & \multirow{3}{*}{$\begin{array}{c}\text { Condition of } \\
\text { the mixing } \\
\text { fans }\end{array}$} & \multirow{3}{*}{$\begin{array}{c}\text { Temperature } \\
\text { differences } \Delta T \\
\left({ }^{\circ} \mathrm{C}\right)\end{array}$} & \multicolumn{6}{|c|}{ Door open time（include door opening time） } \\
\hline & & & $5 \mathrm{~s}$ & $10 \mathrm{~s}$ & $20 \mathrm{~s}$ & $30 \mathrm{~s}$ & $40 \mathrm{~s}$ & $60 \mathrm{~s}$ \\
\hline & & & \multicolumn{6}{|c|}{ Infiltration air volume with $\pm 95 \%$ confidence interval $\left(\mathrm{m}^{3}\right)$} \\
\hline $100 \%$ & off & $50.42 \pm 0.47$ & $4.17 \pm 0.27$ & $9.42 \pm 0.33$ & $19.72 \pm 0.46$ & $31.71 \pm 0.71$ & $42.3 \pm 0.57$ & $61.64 \pm 1.75$ \\
\hline $100 \%$ & off & $33.19 \pm 0.33$ & $4.04 \pm 0.30$ & $7.42 \pm 0.33$ & $16.13 \pm 0.82$ & $25.52 \pm 0.28$ & $34.32 \pm 0.31$ & $50.12 \pm 2.83$ \\
\hline $100 \%$ & on & $33.74 \pm 0.30$ & $3.53 \pm 0.26$ & $6.44 \pm 0.30$ & $11.88 \pm 0.35$ & $17.15 \pm 0.32$ & $21.57 \pm 0.31$ & $32.62 \pm 0.31$ \\
\hline $67 \%$ & off & $29.98 \pm 0.37$ & $2.37 \pm 0.22$ & $4.99 \pm 0.24$ & $10.30 \pm 0.61$ & $16.74 \pm 0.68$ & $23.31 \pm 1.27$ & $34.73 \pm 0.68$ \\
\hline $67 \%$ & on & $29.43 \pm 0.41$ & $2.17 \pm 0.26$ & $3.85 \pm 0.30$ & $7.65 \pm 0.35$ & $10.70 \pm 0.32$ & $14.68 \pm 0.31$ & $21.83 \pm 0.31$ \\
\hline $50 \%$ & off & $48.79 \pm 0.54$ & $2.46 \pm 0.11$ & $5.03 \pm 0.35$ & $10.58 \pm 0.26$ & $16.24 \pm 0.43$ & $21.97 \pm 0.29$ & $35.49 \pm 0.42$ \\
\hline $50 \%$ & on & $48.51 \pm 0.26$ & $2.09 \pm 0.19$ & $3.79 \pm 0.35$ & $7.43 \pm 0.20$ & $10.71 \pm 0.44$ & $13.8 \pm 0.52$ & $20.04 \pm 0.43$ \\
\hline $50 \%$ & off & $30.84 \pm 0.33$ & $1.98 \pm 0.35$ & $4.03 \pm 0.24$ & $7.89 \pm 0.42$ & $12.89 \pm 0.29$ & $17.66 \pm 0.58$ & $28.15 \pm 0.30$ \\
\hline $50 \%$ & on & $30.10 \pm 0.30$ & $1.68 \pm 0.26$ & $2.97 \pm 0.19$ & $5.94 \pm 0.29$ & $8.64 \pm 0.23$ & $11.35 \pm 0.36$ & $16.46 \pm 0.57$ \\
\hline
\end{tabular}


Table 2 Average flow rate (slope of the fitted line in Fig. 4) and the ratio between the flow rates in the case with and without the fans operating

\begin{tabular}{|c|c|c|c|c|}
\hline \multirow{2}{*}{$\begin{array}{c}\text { Temperature } \\
\text { difference }\left({ }^{\circ} \mathrm{C}\right)\end{array}$} & \multirow{2}{*}{ Door opening rates } & \multicolumn{2}{|c|}{ Slope of the fitted line } & \multirow{2}{*}{ Ratio of the slopes } \\
\hline & & Fans off & Fans on & \\
\hline \multirow{3}{*}{50} & $100 \%$ & 1.03 & 0.70 & 1.49 \\
\hline & $67 \%$ & 0.71 & 0.46 & 1.53 \\
\hline & $50 \%$ & 0.57 & 0.34 & 1.66 \\
\hline \multirow{3}{*}{30} & $100 \%$ & 0.84 & 0.55 & 1.52 \\
\hline & $67 \%$ & 0.57 & 0.37 & 1.57 \\
\hline & $50 \%$ & 0.45 & 0.28 & 1.61 \\
\hline
\end{tabular}


Table 3 Comparison results of the ratio between the slopes in Fig. 4 and the ratio between the predicted $Q$ s from Eq. 4 (with same opening rate and state of the cooling fans)

\begin{tabular}{cccccccc}
\hline \multirow{2}{*}{$\begin{array}{c}\text { Door } \\
\text { opening } \\
\text { rates }\end{array}$} & $\begin{array}{c}\text { Condition } \\
\text { of the } \\
\text { mixing } \\
\text { fans }\end{array}$ & $\begin{array}{c}\text { Temperature } \\
\text { difference }\end{array}$ & Initial & Environment & $\begin{array}{c}\text { Ratio } \\
\text { of the } \\
\text { slopes }\end{array}$ & $\begin{array}{c}\text { Ratio of } \\
\text { the } \\
\text { predicted } \\
Q \text { s }\end{array}$ & $\begin{array}{c}\text { Error } \\
(\%)\end{array}$ \\
\hline \multirow{2}{*}{$100 \%$} & Off & $50.42 \pm 0.60$ & 239.47 & 289.89 & 1.23 & 1.27 & 3.31 \\
& & $33.19 \pm 0.43$ & 256.24 & 289.44 & & & \\
$100 \%$ & On & $49.53 \pm 0.96$ & 240.14 & 289.67 & 1.26 & 1.25 & -0.89 \\
& & $33.74 \pm 0.39$ & 255.98 & 289.72 & & & \\
$67 \%$ & Off & $48.69 \pm 0.35$ & 242.53 & 291.22 & 1.25 & 1.31 & 5.35 \\
& & $29.98 \pm 0.48$ & 258.36 & 288.33 & & & \\
$67 \%$ & On & $48.18 \pm 0.35$ & 242.74 & 290.92 & 1.27 & 1.32 & 3.68 \\
& & $29.43 \pm 0.53$ & 258.39 & 287.82 & & & \\
$50 \%$ & Off & $48.79 \pm 0.70$ & 241.21 & 290.00 & 1.26 & 1.30 & 3.22 \\
$50 \%$ & & $30.84 \pm 0.43$ & 259.16 & 290.00 & & & \\
& & $48.51 \pm 0.34$ & 242.03 & 290.54 & 1.22 & 1.31 & 7.33 \\
\hline
\end{tabular}

